\title{
Extinction as a function of reinforcement conditions in the start box
}

GARVIN MCCAIN AND REEVES POWER

ARLINGTON STATE COLLEGE

Groups of rats run in a straight alley differed on the basis of reinforcement conditions in the start box. One group (P) received random 50\% reinforcement, another group (C) had consistent reinforcement conditions. Subgroups of Group $C$ received either $100 \%$ or $0 \%$ reinforcement in the start box. Group $P$ responded differentially on reinforced and nonreinforced trials in acquisition and was more resistant to extinction than Group C.

In the typical "partial reinforcement" study reinforcement or nonreinforcement terminates the performance being measured. In the present study the objective was to examine the effects of partial or consistent reinforcement conditions in the start box (SB) on acquisition and extinction performance as measured between SB and goal box (GB) in a straight alley. There have been a number of studies on prefeeding; these differ markedly from the present study in terms of magnitude of reinforcement and other respects so that, for the present, no comparisons will be attempted.

\section{Method}

Subjects and Apparatus. The Ss were 31 albino rats (Wistar strain) approximately 100 days of age.

The SB and GB each were $12 \mathrm{in.} \mathrm{long} \mathrm{and} \mathrm{separated}$ from a 48 in. alley by guillotine doors. Alley and boxes were 3 in. wide by 5 in. deep and were made of plywood covered with hardware cloth. The SB was painted black. The alley and GB were painted white. A food cup was mounted at the distal end of the GB. A microswitch on the SB door and photoelectric cells in the alley were arranged to measure start time (first 3 in of the alley), running time ( $1 \mathrm{ft}$. section in mid-alley), and goal time (1 ft. section terminating 7-1/2 in. from goal cup)。

Procedure. Ss were maintained on a $23 \mathrm{hr}$. deprivation schedule throughout the handling and running phases. Days 1 thru 10, Ss were handled and gentled. On Day 11, Ss were assigned to individual cages on a random basis. Cage assignment determined running order and group assignment. Usual balancing procedures were used to assign running orders. Prior to feeding on Day 11 Ss were allowed to eat six $97 \mathrm{mg}$ Noyes pellets in their home cage. Beginning on Day 12 Ss were run in squads of six animals. Each $\mathrm{S}$ in a particular squad received one trial, was retained in his waiting cage until each $\mathrm{S}$ in that squad had received a single trial, then the procedure was repeated. On this basis the intertrial interval was approximately 6-8 $\mathrm{min}$. All Ss received 52 acquisition trials, four on the first day of acquisition and six thereafter, followed by 24 extinction trials given six per day.
During acquisition Group P $(\mathrm{N}=10)$ was given $50 \%$ random reinforcement in the $\mathrm{SB}$. For Group $\mathrm{C}(\mathrm{N}=21)$ reinforcement conditions were constant in the $\mathrm{SB}$. Subgroup $C_{N}(N=10)$ was never reinforced in the $S B$, while Subgroup $C_{R}(N=11)$ was reinforced in the $S B$ on all acquisition trials. All Ss were reinforced in the GB on all acquisition trials. Two $97 \mathrm{mg}$ Noyes pellets were used for reinforcement. On reinforced trials Ss remained in the box until the pellets were consumed. When a box was not baited Ss remained in the box $15 \mathrm{sec}$. During extinction no food was available in either SB or GB.

\section{Results and Discussion}

Mean median Running Times from blocks of trials, as indicated, are shown in Fig. 1-a. Start, Running and Goal Time data for the extinction period are plotted in Fig. 1-b. Start and Goal Time analyses are compatible with Running Time results. More detailed information concerning these two measures is available from the senior author. A later study (McCain \& McVean, 1966) using very similar procedures also gives substantial support to the results reported in this paper. Reinforced ( $\mathrm{r}$-trials) and nonreinforced (n-trials) acquisition trials for Group $\mathbf{P}$ are plotted separately and indicate that Ss in Group $P$ tend to run faster on $n$-trials than on $r-$ trials. Analysis of the data gives a significant difference between trial conditions on the first block of acquisition trials $(t=2.77, d f=9, p<.025)$ and over trials $6-52$ as well $(t=2.81, d f=9, p<.025)$. Trial blocks including trials 6-52 for Groups $P$ and $C$ were compared using a Mann-Whitney $U$ test. Group $P$ does not differ from Group $C$ on $n$-trials ( $p>$.14) but does have significantly longer running times on r-trials for both the first block of trials $(p<.02)$ and trials $6-52(p<.055)$. The general performance of Group $P$ is similar to groups run in the usual frustration study except that performance on ntrials is not more vigorous than the consistent groups. Also, the difference on $\mathrm{r}$ - and n-trials is evident on the first day of acquisition. This is earlier than would be anticipated from a frustration standpoint. Acquisition results constitute the principal differences between Goal and Running Times. Based on the Goal Times measure there is no difference in $n$ - and $r$-times nor does Group $P$ differ on either measure from Group C.

Analysis of Running Time data indicates Group $P$ is significantly more resistant to extinction than Group $\mathrm{C}(\mathrm{p}<.05)$. These data were also analy zed with Subgroups $\mathrm{C}_{\mathrm{N}}$ and $\mathrm{C}_{\mathrm{R}}$ separated. In this analysis there is an overall group difference $(F=3.80, \mathrm{df}=2 / 28, \mathrm{p}<.05)$. Individual $t$ tests indicate Group $P$ differs significantly from 


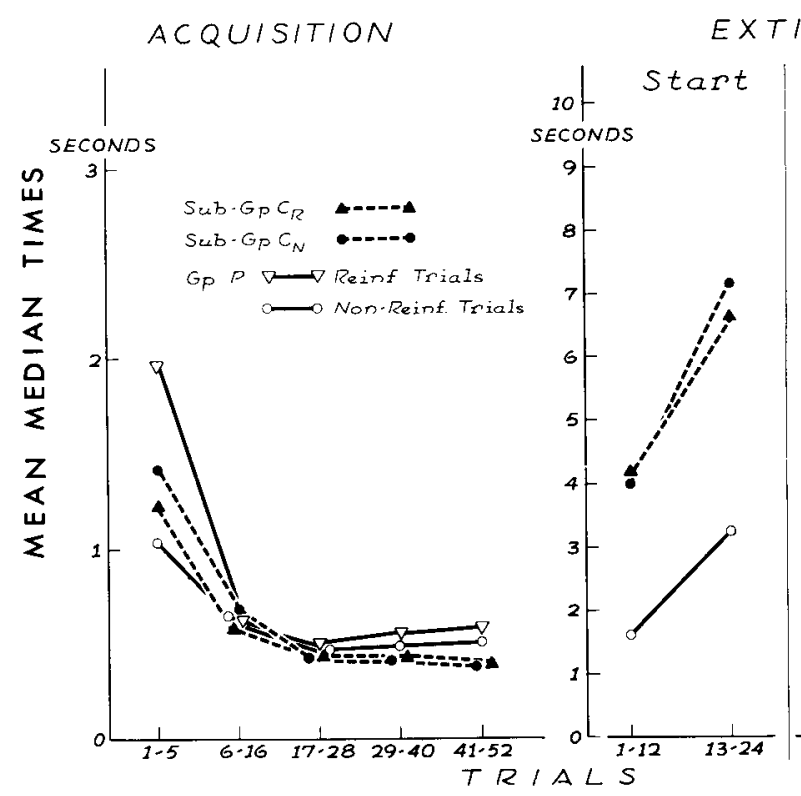

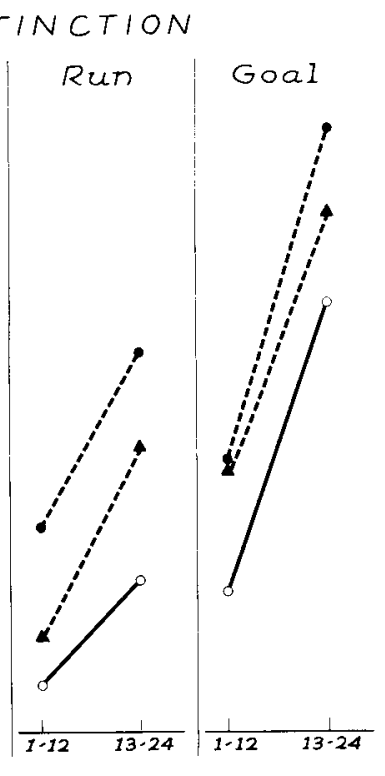

Fig. 1-a. Mean median running times during acquisition. Fig. 1-b. Mean median start, run and goal times from blocks of 12 trials during extinction.
Subgroup $\mathrm{C}_{\mathrm{N}}(\mathrm{t}=2.49, \mathrm{df}=18, \mathrm{p}<.025)$ and substantially $(t=1.62)$ but not significantly from Subgroup $C_{R}$. The difference between Subgroups $C_{N}$ and $C_{R}$ is slight $(t=.82)$.

The extinction data may be related to at least two current notions regarding partial reinforcement, the frustration hypothesis (Amsel, 1958) and the revised aftereffects hypothesis (Capaldi \& Senko, 1962; Capaldi \& Stanley, 1963). If only extinction data are considered they are compatible with the frustration hypothesis. It could be assumed $r_{f}-s_{f}$ has been evoked by start box conditions for Group $P$ and that $\mathrm{s}_{\mathrm{f}}$ has become associated with the running response. As indicated earlier, the acquisition data present problems if considered in terms of the usual assumptions, e.g., Amsel (1958), regarding frustration. It is not clear why acquisition data in this study and McCain \& McVean (Experiment 2, 1966) differ from typical double alley data. It is not apparent whether or not these acquisition data can be interpreted in terms of the frustration hypothesis.

If the data are analyzed in terms of aftereffects, it could be assumed that during the acquisition phase SB conditions produce distinctive stimuli and these stimuli become a part of the stimulus compound related to the locomotion response. It might be further assumed that the changes in reinforcement conditions in Group
P produce strong (but unspecified) emotional responses. Both consistent reinforcement conditions could produce distinctive cues but without any strong emotional arousal. In this situation the emotional responses evoked by the GB might provide a salient cue during the extinction period. An aftereffects explanation does not account for the differences in performance in acquisition.

While it is interesting to speculate regarding these results the explanations considered were applied to the results rather than predicting the events. Atpresent the principal value of this study is to provide a somewhat different technique for examination of old problems.

\section{References}

Amsel, A. The role of frustrative nonreward in noncontinuous reward situations. Psychol. Bull., 1958, 55, 102-119.

Capaldi, E. J., \& Senko, M. G. Acquisition and transfer in partial reinforcement. J. exp. Psychol., 1962, 63, 155-159.

Capaldi, E. J., \& Stanley, L. R. Temporal properties of reinforcement aftereffects. J. exp. Psychol., 1963, 65, 169-175.

McCain, G., \& McVean, G. Performance in a straight alley following inconsistent or consistent reinforcement in the start box. Paper read at Midwestern Psychological Association Meeting, May, 1966.

\section{Note}

1. Some of these data were reported at Midwestern Psychological Association Convention, May, 1966. 